\title{
Los mecanismos de extrañamiento en Amor de Don Perlimplín con Belisa en su jardín de Federico García Lorca
}

\author{
Mechanisms of Estrangement in Love of Don Perlimplin \\ and Belisa in his Garden from Federico García Lorca
}

\author{
Claudia L. Gutiérrez Piña \\ Universidad de Guanajuato
}

\section{RESUMEN}

Amor de Don Perlimplín con Belisa en su jardín es una de las obras menos privilegiadas por la crítica lorquiana, a pesar de ser una pieza magníficamente lograda. En ella, García Lorca hace uso de procedimientos teatrales que pertenecen a distintos géneros y tonos, con la finalidad de desestabilizar la percepción de las acciones representadas. Estos mecanismos de extrañamiento derivan en la transformación gradual del personaje principal y de la visión de mundo que éste proyecta, como producto de un movimiento que transita de la farsa a la tragedia.

Palabras Clave: extrañamiento; farsa; tragedia; Don Perlimplín; Lorca.

\section{ABSTRACT}

Love of Don Perlimplin and Belisa in his Garden is one of the underprivileged works by Lorca's critics, despite being a piece magnificently achieved. In it, García Lorca uses theater procedures that belong to different genres and tones, in order to destabilize the perception of the represented shares. These mechanisms of estrangement derive in the gradual transformation of the main character and the vision of the world that it projects, as result of a movement that transits from farce to tragedy.

Key words: estrangement; farce; tragedy; Don Perlimplín; Lorca.

En uno de los bocetos de la obra Amor de Don Perlimplín con Belisa en su jardín, Federico García Lorca anotó: «el personaje no se debe dar cuenta de nada, pero sí el público. El drama debe estar en el público pero no en los personajes» (García Lorca, 1990: 39) ${ }^{1}$. En estas palabras, reveladoras del pro-

\footnotetext{
${ }^{1}$ Los bocetos de la obra, según registra Margarita Ucelay (1990), datan de los años 19221926. En 1927 la obra estaba lista para su estreno en Madrid, aunque éste se concretaría
} 
ceso creativo del poeta, se encuentra el germen de lo que otorgará singularidad a su pieza: el juego constante de mecanismos de extrañamiento, es decir, aquellos procedimientos que desestabilizan la percepción en el lector/espectador de las acciones representadas. En este ejercicio, Don Perlimplín representa una pieza clave en el corpus de la obra lorquina por el delicado trabajo poético que guarda y la destreza del autor en el uso de los recursos dramáticos. Sin embargo, dentro de la monumental crítica del autor, Don Perlimplín es una de las obras menos privilegiadas. Margarita Ucelay, en su valioso trabajo a propósito de la edición de esta pieza, ponderó por ello la necesidad de rescatarla de una cierta posición marginal: «Publicada a la sombra de las obras «mayores» del poeta, olvidada por el teatro profesional, sólo cuenta con un número reducido de estudios, en la inmensidad de la bibliografía lorquiana. Es, sin embargo, una creación clave» (1990: 11).

$\mathrm{Si}$ bien es cierto que en proporción con las obras «mayores» a las que refiere Ucelay, Don Perlimplín cuenta con pocos estudios, éstos han gestado una línea de lectura un tanto generalizada que subraya la mezcla de recursos genéricos y de tonos que operan en esta obra. Aunque la mayor parte reconoce la hibridez como su característica esencial, todos coinciden en destacar lo que hay en ella de farsa. Alfredo de la Guardia parece ser uno de los primeros en señalarlo, aunque su valoración no favoreció del todo a la obra, al compararla con La zapatera prodigiosa que ve como su antecedente. Según De la Guardia, Don Perlimplín «sigue la línea de la farsa, repitiendo el mismo espíritu [de La zapatera prodigiosa], pero en evidente descenso, pues su vuelo es más corto y más pobre» (1961: 299). Francis Ferguson, por su parte, añade a la farsa la presencia del tópico «Liebestod», unión que reconoce como extravagante, pero que, «mediante el estilo de la pieza, consigue una aceptable fusión de elementos tan dispares» (1998: 179). Para Gwynne Edwards, se trata de una farsa en la que «el tema del viejo que se casa con la joven aparece tratado cada vez con mayor seriedad» (1983: 61). Francisco García Lorca atina en reconocer que la farsa en Don Perlimplín está «orientada hacia una exquisita, punzante y lírica musicalización» (1998: 319) y asume su condición genérica como una farsa lírica.

Margarita Ucelay, por su parte, retoma las declaraciones de Lorca respecto a las denominaciones que dio a su obra: «una obra grotesca», «aleluya erótica», «tragedia grotesca», «una obra tremenda», «versión de cámara», «vocero de un drama grande», «una operita de cámara», «una cosita ligera» (1990: 184). Al respecto, Ucelay subraya las dificultades del autor para definir «su criatura», porque todas las categorías mencionadas se ajustan a las característi-

hasta 1933. La obra se publica por primera vez en Buenos Aires en 1938, con el sello de Losada, en plena Guerra Civil española y cuando Lorca ya había muerto. Ucelay relata los contratiempos que sufrió esta obra antes de que pudiera ser llevada a escena: fue incautada por la policía y retenida por ser considerada «inmoral». 
cas de Don Perlimplín. Así que opta por considerar la obra como sui generis y agrega: «es una síntesis de los elementos más dispares, irreconciliables hasta aquí en la tradición literaria, porque el Perlimplín es farsa y tragedia, es candoroso y lascivo, bufo y lírico, grotesco y sublime» (1990: 184). En el mismo sentido se encuentra el estudio de Enric Bou, quien asume para la definición de la obra lorquiana el término de «tragedia grotesca» (2000: 77), mientras que para Ricardo Doménech es «una obra que empieza siendo una farsa y acaba siendo una auténtica tragedia» (2008: 242).

Al retomar lo apuntado por los críticos, destaca la nota de elementos que se apartan de una mera discusión sobre el género, como lo bufo, que más que género es un tono, y lo grotesco, cuyos recursos apoyan la consecución de un efecto de sentido. Por todas las contrariedades con las que el lector/espectador de esta obra lorquiana tiene que enfrentarse, lo importante para entender su funcionamiento es reconocer cuáles son los efectos que el autor persigue con cada recurso empleado para configurar una propuesta dramática que responda a sus preocupaciones artísticas más entrañables. Si bien en los acercamientos críticos con los que cuenta la obra se ha puntualizado su condición híbrida, queda aún por reconocer cuáles son los «giros» que se promueven en su configuración dramática y que determinan dicha hibridez. Por lo anterior, considero pertinente una revisión de los elementos que hasta aquí he anotado como atribuidos a Don Perlimplín. Mi propuesta de lectura se ciñe, por lo tanto, al rastreo de los recursos más significativos que definen la transformación constante de las acciones representadas en la obra, como producto de un movimiento que transita de la farsa a la tragedia y que deriva en la transformación del personaje principal y de la visión de mundo que proyecta.

Parto del elemento que presenta uno de los polos de tensión de la obra, lo cómico, del que se desprende la noción de la farsa. Hablo de lo cómico como recurso para la búsqueda de un efecto, y no de la comedia como género en el sentido aristotélico, lo cual ya entraña su propia dificultad. Según Patrice Pavis, lo cómico está relacionado con la intención estética que busca como efecto la risa a partir de la reelaboración de situaciones, discursos o formas que pueden ser simpáticas o antipáticas; en el primer caso, encontramos un divertimento placentero, mientras que en el segundo se implica un cariz negativo debido a una intención ridiculizante. Hablar de lo cómico supone, entonces, acceder al mundo de la risa bajo cualquiera de sus formas (Pavis, 1980: 76-81).

Hasta la fecha, uno de los planteamientos más propositivos sobre el funcionamiento de la risa sigue siendo el del filósofo francés Henri Bergson, quien reconoce que lo cómico se manifiesta mediante mecanismos que dan un efecto de automatismo y rigidez: «las actitudes, gestos y movimientos del cuerpo humano causan risa en la exacta medida en que dicho cuerpo nos hace pensar en algo simplemente mecánico» (1973: 34). Este principio de lo mecánico vale para todos los niveles: gestualidad rígida, repeticiones verbales, serie 
de efectos burlescos, estereotipos retóricos e ideológicos, juegos de palabras, etc. Los principios donde estos mecanismos son desarrollados originan la comicidad de situación, comicidad de palabra o comicidad de caracteres.

La farsa, género perteneciente a la comedia y que ha evolucionado desde la época griega hasta sus manifestaciones modernas ${ }^{2}$, hace uso particular de los recursos de lo cómico. Según señala Pavis, «En el género cómico, la crítica opone la farsa a la comedia de estilo e intriga donde triunfan el espíritu, la intelectualidad y la palabra sutil» (1980: 218). Por el contrario, la farsa posee cierta tosquedad en sus recursos, ya que su propósito recae en la búsqueda de una risa franca, liberadora: «los impulsos y la risa liberadora triunfan ante la inhibición y la angustia trágica, bajo la máscara de la bufonería y de la "licencia poética"» (Pavis, 1980: 219). El propósito de la farsa es divertir, «con una risa grosera» (Pavis, 1980: 219), por ello es importante la exageración en gestos, posturas y tonalidad.

Para identificar los elementos de la farsa que operan en Don Perlimplín, es necesario ubicar la influencia de este género en el ambiente del teatro español de la época. A propósito, Emilio Peral reconoce entre 1982 y 1939 un periodo de resurgimiento de la farsa debido a la búsqueda de una «reteatralización de la escena» (2008: 1074) vía la recuperación de las formas breves del Siglo de Oro y el gesto lúdico de las vanguardias europeas. De ahí que Rubio Jiménez acote como una de las tendencias teatrales en España durante la segunda década del siglo XX lo que denomina como «farsa poética». De acuerdo con este autor, «En la farsa de los años 20 confluyen la recuperación de los clásicos [...] con autores contemporáneos [...] Y no menos la influencia de formas populares como la commedia dell'arte, el entremés, los títeres o los llamados género chico e ínfimo» (1992: 258). A los modelos citados, Rubio Jiménez añade el modelo de pastiche literario, por la frecuencia con que los dramas de la época se construyeron como una especie de mosaico donde participaban tradiciones múltiples. Esta observación nos acerca a Don Perlimplín, donde, además del empleo de los recursos clásicos de la farsa, se encuentra la fusión de otras tradiciones, como es el entremés y la plasticidad del aleluya. Tradiciones de las que abreva pero de las que también se distancia.

Los recursos de la farsa (búsqueda de efecto cómico, gestos, movimientos y tono exagerado) se perciben en Don Perlimplín desde el cuadro primero, aunque, como se verá, irá modificando o añadiendo recursos para provocar cambios que se traducirán en mecanismos de extrañamiento, como anoté al inicio de este

\footnotetext{
${ }^{2}$ Pavis recuerda que las primeras manifestaciones de la farsa se remontan a la literatura griega antigua, con las obras de Aristófanes, y a la latina, con Plauto. Sin embargo, la constitución del género se logra en el curso de la Edad Media, se prolonga hasta comienzos del siglo XVII, cuando «se amalgama en la comedia de intriga de Moliere. Autores de vaudeville como Labiche, Feydeau o Courteline, o los dramas del absurdo (Ionesco, Beckett, J. Díaz) perpetúan en nuestro tiempo la tradición de lo bruto cómico y del sin sentido» (Pavis, 1980: 218).
} 
escrito. Reitero que el extrañamiento debe entenderse como efecto de los procedimientos artísticos, en este caso teatrales, que buscan desestabilizar la percepción que el lector/espectador tiene de las acciones representadas. Es decir, sugiere la conversión de lo habitual en extraño, presentándolo bajo una nueva luz y situándolo en un contexto inesperado. El término remite de manera inmediata a la propuesta de los formalistas rusos, particularmente a la noción ostranenie de Shklovski, cuya reflexión a propósito del lenguaje poético (o artístico) reconoce su capacidad para desautomatizar las formas familiares, sean lingüísticas, genéricas o de visión de mundo (2007: 60). En el caso de Don Perlimplín, para lograr el efecto enunciado, los mecanismos de esta desautomatización operan en el nivel de la articulación de formas genéricas utilizadas. Se trata de que el espectador se vea asaltado por la materialidad del aparato escénico y se retraiga o extrañe ante las desviaciones graduales de lo que pudiera percibirse en un momento dado como un continuo.

La obra inicia con el diálogo entre Perlimplín y Marcolfa, donde se introduce el tema que estructura las acciones de la obra, el tema del viejo que se casa con la joven, argumento que es tradicional de la farsa y que además establece una relación intratextual en la obra lorquiana con la historia de $L a$ zapatera prodigiosa. Es importante notar que, aunque las dos obras retoman un tema que tiene larga tradición teatral, cada una lo lleva a una finalidad estética distinta. Mientras que en La zapatera prodigiosa el juego de los tonos cómicos se mantiene más o menos estable, en Don Perlimplín se articula mediante variaciones en el ritmo que desembocan en un singular patetismo.

El acto primero, donde se pacta el matrimonio entre Belisa y Perlimplín, se apega, aparentemente, a la tradición de la farsa. El diálogo inicial entre Perlimplín y Marcolfa, ésta una típica criada de las que abundan en la comedia, establece un ritmo inicial que acerca la escena a la situación cómica:

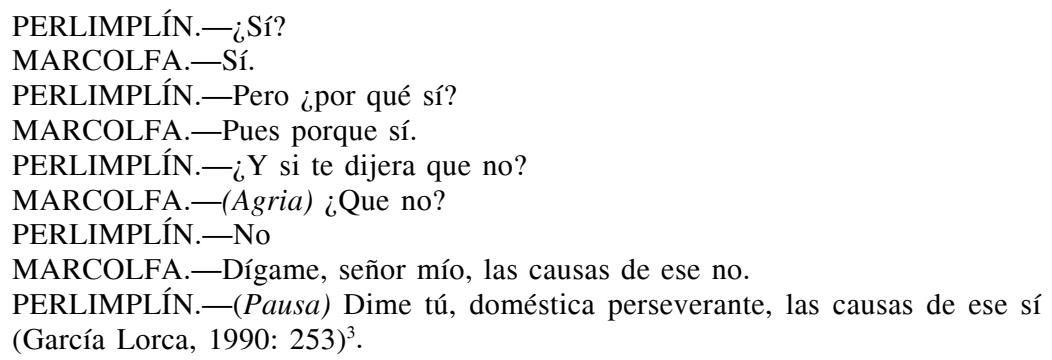

Este diálogo, semántica y fonéticamente, es un juego. Juego que presenta la repetición como recurso cómico. La disposición alternada de los adverbios afirmativo y negativo otorga a esta primera escena un tono que si no es en sí

\footnotetext{
${ }^{3}$ Todas las citas del texto pertenecen a esta edición, en adelante sólo consignaré el número de página.
} 
mismo cómico, abre camino a la operación ridiculizante del personaje. Como señala Bergson, «la repetición de una frase no causa risa por sí misma. Sólo nos hace reír porque simboliza una determinada combinación particular de elementos morales, símbolo a su vez de una combinación enteramente material» (1973: 66). El juego de palabras descubre la personalidad de Perlimplín, viejo con actitudes infantiles, cuya voluntad es manejada por su criada Marcolfa, quien, fiel al personaje tipo, pone en cauce las decisiones de su señor ${ }^{4}$. Sin embargo, si Lorca recurre a esta situación tradicional entre señor y criado, es claro también que hay la intención de puntualizar, a partir del breve juego de palabras, la posición que tiene su personaje respecto a la tradición de la que está echando mano: el amor entre el viejo y la niña.

El «sí», causa de la disparidad de opinión entre los personajes, cuenta con la acepción semántica del consentimiento del matrimonio, que recuerda, en la tradición literaria del viejo y la niña, El sí de las niñas de Moratín. Pero aquí el problema no radica en el sí de Belisa, sino en el de Perlimplín, lo que comienza a definir su carácter ridículo:

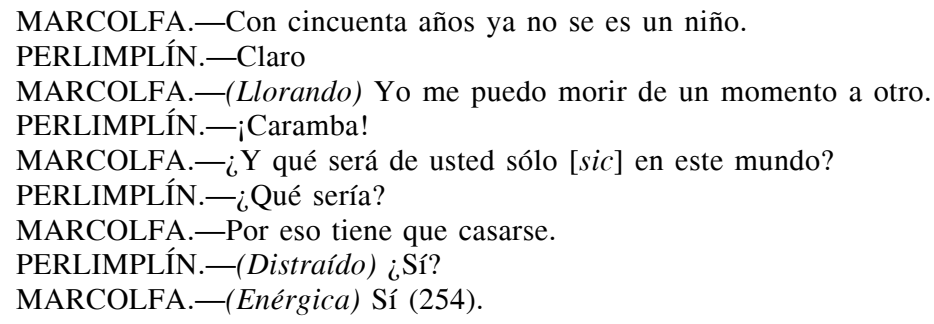

La aparición de Belisa en escena acentúa el carácter risible de Perlimplín. La apariencia de Belisa, no sólo joven, sino llena de sensualidad: «aparece BELISA resplandeciente de hermosura. Está medio desnuda» (255), contrasta con la imagen de Perlimplín, quien «viste casaca verde y peluca blanca llena de bucles» (253). Como señala Luis Fernández Cifuentes, «el viejo y la niña son, antes que nada, un conflicto visual» (1992: 89). Sin embargo en Don Perlimplín este efecto de contraste no se sustenta en la diferencia de edades. En realidad el carácter risible de Perlimplín no es tanto su vejez, contrastada con la juventud de Belisa, sino su actitud infantil y su falta de voluntad. En este caso, el procedimiento de la fabricación de lo cómico, como señala Bergson, recae en el recurso del «títere de cordelillos», es decir, el efecto de marionetización que sufre el personaje:

Todo lo serio de la vida proviene de nuestra libertad. Los sentimientos que hemos madurado, las pasiones que hemos incubado y las acciones que hemos deli-

\footnotetext{
${ }^{4}$ Como personaje tipo, «El criado es siempre quien confronta al personaje principal, el que lo fuerza a actuar, a expresarse, a revelar sus sentimientos, a ejecutar las tareas poco dignas de los aristócratas y burgueses» (Pavis, 1980: 106).
} 
berado, determinado y ejecutado, lo que, en suma, proviene de nosotros y es bien nuestro, eso es lo que da a la vida su aspecto a veces dramático y, en general, grave. ¿Qué es lo que haría falta para transformar todo eso en comedia? Habría que imaginarse que la aparente libertad encubre unos hilos y que [...] somos aquí abajo... humildes marionetas (1973: 71).

Este efecto de marionetización se presenta en Don Perlimplín con el manejo de voluntad que Marcolfa ejerce sobre Perlimplín para forzar el encuentro entre éste y Belisa:

MARCOLFA.-Esa es la mujer de mi señor. La blanca Belisa.

PERLIMPLÍN.-Belisa... Pero no sería mejor...

MARCOLFA.-No... venga ahora mismo. (Le coge de la mano y se acercan al balcón) Diga usted Belisa...

PERLIMPLÍN.-Belisa...

MARCOLFA.-Más alto.

PERLIMPLÍN._-¡Belisa!...

$[\ldots]$

BELISA.- ¿Quién me llama?

MARCOLFA.-(Escondiéndose detrás de la cortina del balcón) Conteste (255-256).

El movimiento de Marcolfa señalado en la última acotación, acentúa el efecto pretendido; escondida detrás de la cortina, se le ve en el papel de la marionetista que mueve los hilos de Perlimplín a la vez que le da su voz ${ }^{5}$.

Poco a poco el cuadro va descubriendo los lugares comunes de la tradición literaria evocada, sin perder el tono de la farsa. La Madre, ridiculizada por el exceso de sus vestidos (aparece «con una gran peluca dieciochesca llena de pájaros, cintas y abalorios», 256), funge, al igual que Marcolfa, como casamentera. Dicho personaje, cuya participación se reduce a esta única escena en toda la obra, reproduce la imagen de la viuda cuyo interés se centra en acomodar a la hija en un matrimonio que asegure su estabilidad económica: «Don Perlimplín tiene muchas tierras. En las tierras hay muchos gansos y ovejas. Las ovejas se llevan al mercado. En el mercado dan dinero por ellas. Los dineros dan la hermosura... Y la hermosura es codiciada para los demás hombres» (257). Este último comentario, además de definir las intenciones del matrimonio entre Belisa y Perlimplín, funciona como augurio de la futura infidelidad de Belisa.

A pesar de la brevedad del acto, característica general de la obra, el espectador/lector ha recibido una importante carga de información. Lorca parece concentrarse en presentar rasgos elementales de la trama, que permitan ubicarla en la tradición literaria ya señalada. Esto para posicionar al receptor en un aparen-

\footnotetext{
${ }^{5}$ Es necesario notar, desde este momento, que el mismo mecanismo, el del manejo de la voluntad del otro, se verá retomado en los actos posteriores para lograr efectos distintos que derivan en la transformación tanto del personaje como de la visión de mundo que se representa en escena.
} 
te supuesto, lo cual permitirá que las operaciones que rompan con ese supuesto cumplan precisamente con el efecto de extrañamiento. Este efecto se insinúa por primera vez al final del primer acto, en el momento en que Perlimplín exclama: «Y qué es esto que me pasa?... ¿qué es esto?»(259). Las palabras de Perlimplín son acompañadas por la ejecución del piano y, en el escenario, por la aparición de una bandada de pájaros de papel negro, que resultan ser indicios de que algo está por suceder. Como señala Ucelay, bajo la aparente sencillez del acto se presiente «algo siniestro, oscuro, apenas expresado en símbolos o palabras premonitorias, ya sean las «cosas ocultas» que menciona Marcolfa, o los pájaros negros que cruzan entre los dos balcones» (1990: 193).

Este presentimiento rompe ligeramente el ritmo llevado hasta el momento en el acto. Es como si una especie de «distorsión»o «disonancia», un pequeño movimiento, se presentara para romper con la armonía establecida. La analogía musical no es gratuita si se considera que la configuración de Don Perlimplín se sustenta, en gran parte, en el acompañamiento de las piezas musicales, como las sonatinas y las canciones. A esto se aúna la nota en el título de la obra, «versión de cámara». Respecto del acompañamiento musical, Luis T. González del Valle y Francisco García Lorca han subrayado la importancia de las piezas aludidas, así como el ritmo que la misma obra va marcando para su desarrollo. González del Valle (1980) equipara la obra a la estructura del allegro de sonata, a partir de la particularidad de este tipo de composición, en la cual se entrelazan dos temas contrastantes. Francisco García Lorca (1998), por su parte, analiza el patrón rítmico del primer diálogo para hacer notar la intención musical de Don Perlimplín, dando pie a la duda de si en realidad el autor habría tenido la intención de hacer un libreto de ópera. Lo cierto es que en Don Perlimplín es perceptible un ritmo marcado tanto en los diálogos como en la articulación de las acciones, lo cual habla de la consciencia poética de Lorca y del temperamento lírico que caracteriza su obra.

El ritmo establecido en el cuadro primero continúa en el siguiente, en el que se representa la noche de bodas. Se observa, sin embargo, un ligero cambio en el discurso de los personajes. Si en el primer cuadro se privilegiaron las frases cortas y el movimiento físico para dar agilidad a las escenas y a los recursos cómicos, en el segundo cuadro se presenta un discurso más elaborado, tanto en Perlimplín como en Belisa, lo cual implica un intento por profundizar el carácter de los personajes, característica que, principalmente en Perlimplín, lo irá alejando paulatinamente del mero tratamiento cómico:

PERLIMPLÍN.- - [...] Belisa.... Con tantos encajes pareces una ola y me das el mismo miedo que de niño tuve al mar. Desde que tú viniste de la iglesia está mi casa llena de rumores secretos y el agua se entibia ella sola en los vasos... ¡Ay!... Perlimplín... ¿dóndes estás, Perlimplín? (261).

La cita anterior introduce una «distorsión» en el ritmo de la obra: la experiencia íntima de Perlimplín revelada en este pequeño monólogo, dota a la 
escena de un tono lírico que contrasta con la percepción del Perlimplín marionetizado del cuadro anterior ${ }^{6}$. El personaje habla aquí por sí mismo, y su monólogo, aunque breve, anticipa la tensión dramática de su desdoblamiento, que será en los cuadros siguientes el tema guía del tratamiento del personaje hasta el desenlace. Los «rumores secretos» marcan la pauta para un juego de ocultamiento que en los cuadros siguientes intensificarán el efecto de extrañamiento, desplegado por medio de la tensión entre lo que se ve y lo que se insinúa.

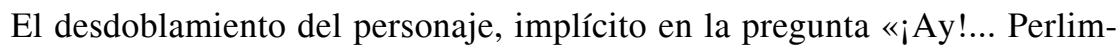
plín... ¿dóndes estás, Perlimplín?», se ve desplazado a otro tipo de acción teatral cuando aparecen los duendes. Esta escena se presenta como un juego en el que se sobreponen distintos niveles de realidad, de tal manera que la realidad teatral se desdobla para mirarse a sí misma.

(Dos duendes saliendo por los lados opuestos del escenario corren una cortina de tonos grises. Queda el teatro en penumbra, con dulce tono de sueño. Suenan flautas. Deben ser dos niños. Se sientan en la concha del apuntador de cara al público). DUENDE $1 .{ }^{\circ}-i$ Cómo te va por lo oscurillo?

DUENDE $2 .^{\circ}-\mathrm{Ni}$ bien ni mal compadrillo.

DUENDE $10^{\circ}-\mathrm{Ya}$ estamos.

DUENDE $2 .^{\circ}-$ Y qué te parece. Siempre es bonito tapar las faltas ajenas.

DUENDE $10^{\circ}-\mathrm{Y}$ que luego el público se encargue de destaparlas... (265).

El apelativo al público resulta ser el recurso tradicional para incorporar el efecto de extrañamiento, porque rompe con la dinámica de la ilusión o efecto de realidad de la obra. Regularmente esta ruptura de las convenciones que rigen los esquemas de la actividad teatral tiene la finalidad de producir la sensación en el público de formar parte de la representación y, a la vez, de estarla viendo. Como señala Pavis, «la fascinación ejercida por esta forma es en definitiva la de mirarse a sí mismo, la de invertir los signos de la relación teatral, la de ser a la vez actor y espectador» (1980: 491).

El efecto que logra la irrupción de estos duendes comporta, según Bou, un doble sentido: «establecer este doble nivel de la acción y advertir, al pretender ocultar, de la singularidad moral de la obra» (2000: 87). Creo que, en efecto, se juega con esta doble intencionalidad, pero Bou deja fuera el elemento de incorporación del público, esencial para distinguir cómo se transformará la percepción del personaje, porque con este recurso hay un cambio en la apreciación de la realidad teatral, que se amplía para abarcar también esa otra realidad tridimensional donde el público se ve incluido:

\footnotetext{
${ }^{6}$ A propósito, Emilio Peral habla de un efecto de «humanización del tipo cornudo» ejercido en el personaje de Perlimplín, en función del diálogo con la tradición de la burla clásica-burla moderna que reconoce en el texto lorquiano, ligado con la hibridación de la máscara Pantalone, «viejo irrisorio», y Pierrot, «símbolo del fracaso amoroso» (2001: 239).
} 
DUENDE $2 .^{\circ}$-Porque si las cosas no se cubren con toda clase de precauciones... DUENDE $10^{\circ}-$ No se descubren nunca.

DUENDE $2 .^{\circ}-\mathrm{Y}$ sin ese tapar y destapar...

DUENDE $1 .^{\circ}$ - $Q$ Qué sería de las pobres gentes!

DUENDE $2 .^{\circ}$-(Mirando la cortina) iQue no quede ni una rendija!

DUENDE $10^{\circ}-$ Que las rendijas de ahora son oscuridad mañana. (Ríen.)

DUENDE $2 .^{\circ}$ - Cuando las cosas están claras...

DUENDE $1 .^{\circ}$-El hombre se figura que no tiene necesidad de descubrirlas.

DUENDE $2 .^{\circ}-\mathrm{Y}$ se van a las cosas turbias para descubrir en ellas secretos que ya sabía (265).

El tono de los duendes comporta, más allá de lo jocoso y lúdico, un sentido encubierto que resulta perturbador porque atañe al espectador. Las «pobres gentes» a las que aluden son, en efecto, el público, que se halla manejado por los caprichos de estos duendes. Hay, en este sentido, una identificación del público con el personaje, porque el espectador se descubre, como Perlimplín, a expensas de las voluntades caprichosas de un otro. El efecto perturbador, producto del extrañamiento, radica en que al público se le hagan evidentes los hilos que los convierten también, parafraseando a Bergson, en «humildes marionetas». Así, la risa libre, grosera, provocada por los recursos de la farsa hasta aquí utilizados, comienza a tornarse en una tímida mueca en los labios del espectador.

La importancia de esta escena radica en que marca la pauta para que los recursos que hasta ahora se habían presentado puramente cómicos se muestren velados por un sentido otro, oculto pero latente. De ahí que la escena que exhibe a Perlimplín como el gran cornudo, permita ese juego que Edwards refiere como «un bello equilibrio entre lo cómico de la situación y esos otros aspectos más serios y conmovedores» (1983: 62). En efecto, si la imagen de Perlimplín al despertar tras la noche de bodas «con unos grandes cuernos de ciervo en la cabeza» (269) es risible por la ridiculización, no sólo visual, sino moral que implica el símbolo de los cuernos, este efecto cómico irá tomando un cariz patético, conmovedor, al final del cuadro:

PERLIMPLÍN.-Nunca había visto la salida del sol... (Belisa, rendida, cae sobre las almohadas.) Es un espectáculo que.... parece mentira... ¡me conmueve!... ¿ $\mathrm{Y}$ a ti? ¿no te gusta? (Se dirige hacia el lecho.) Belisa, ¿estás dormida?

BELISA.-(Entre sueños) Sí (271).

El despertar de Perlimplín es un despertar simbólico al amor, que se presenta como herida que sangra, deseo que duele, como expresa su canción:

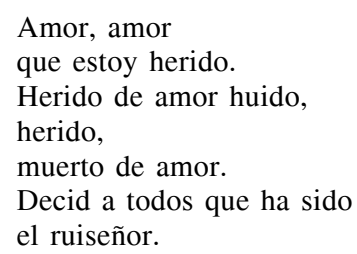




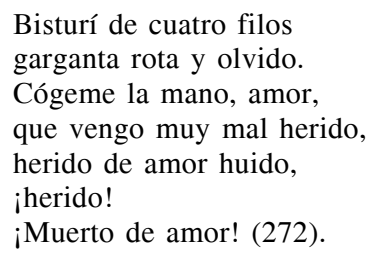

El canto de Perlimplín implica un radical cambio. Un personaje es cómico, según Bergson, «en la medida exacta en que se ignora a sí mismo», porque lo cómico «es inconsciente. Como si se usara al revés el anillo de Giges, se hace invisible a sí mismo, haciéndose visible a todo el mundo» (1973: 2425). En este sentido, el cierre de este acto, con la actitud intimista de Perlimplín cantando y reconociéndose como «herido, muerto de amor», implica un vuelco en su configuración cómica. La escena, además de servir como adelanto del desenlace funesto, sigue la lógica de «mostrar y ocultar» que ha marcado pauta en la obra con la entrada de los duendes. Este juego provoca el extrañamiento en la percepción del personaje que permitirá intuir, en los cuadros siguientes, una oscuridad latente, pero aún oculta.

La transformación de Perlimplín se traduce a partir del cuadro tercero en una inversión de papeles. Si hasta la noche de bodas Perlimplín fue la marioneta, ahora se convierte en marionetista. Un nuevo juego de teatro en el teatro aparece en el nivel de las acciones representadas. El cuadro abre con un diálogo entre Perlimplín y Marcolfa, quien es dirigida para hacer «algo»:

PERLIMPLÍN.-¿LLo harás como te digo?

MARCOLFA.-(Llorando) Descuide el señor (276).

El pronombre «lo» sugiere la existencia de algo que se mantiene oculto, un código cifrado entre los personajes que queda vedado para el espectador, pero del que se presentarán indicios que tendrán que ser puestos en claro, porque, como señalaron los duendes «Cuando las cosas están claras... El hombre se figura que no tiene necesidad de descubrirlas» (265).

La metateatralidad que comienza a desplegarse gracias a Perlimplín se intuye en su diálogo con Belisa después de que la piedra envuelta en una carta es arrojada por el balcón ${ }^{7}$.

BELISA.—¡Perlimplín! ¡No la leas!

PERLIMPLÍN.-(Poniéndose fuerte en broma) ¿Qué quieres decir?

BELISA.-(Llorando) ¡Dame esa carta!

PERLIMPLÍN.-(Acercándose) ¡Pobre Belisa! Porque comprendo tu estado de ánimo te entrego este papel que tanto supone para ti... (BELISA coge el papel y lo guarda en el pecho.) Yo me doy cuenta de las cosas. Y aunque me hieren profundamente comprendo que vives un drama (276).

\footnotetext{
${ }^{7}$ El espectador entenderá, pero sólo después, que el arrojo de esta carta por el balcón es lo que pidió Perlimplín a Marcolfa que hiciera.
} 
La acotación de Perlimplín, «poniéndose fuerte en broma», implica la conciencia de estar adoptando un personaje, así como la frase que ubica a Belisa en «un drama», que ahora es dirigido por el propio Perlimplín. Los recursos cómicos en este acto mantienen su presencia con la tensión irónica de las frases de Belisa sobre su fidelidad «No conocí más hombre que mi Perlimplinillo» (276) y, refiriéndose a las cartas de sus amantes «... que no he contestado porque tenía mi maridito» (277). El ritmo de la obra se ha modificado, si antes las «distorsiones», producto de los efectos del extrañamiento se superponían sobre el tono de la farsa, ahora son los elementos cómicos los que perturban un tono que privilegia la incertidumbre del ocultamiento, como acentúan las palabras finales del personaje en este cuadro: «¡Más tarde lo sabrás todo! ¡Más tarde!» (279), comentario que atañe también al espectador.

El cuadro final de la obra presenta, desde el aspecto visual, un cambio significativo que, como se verá, tendrá gran influencia en el modo como se percibirá el desenlace. Los cuadros anteriores mantuvieron, como constante en el escenario, el juego visual con las viñetas de los aleluyas, tradición que también participa en la configuración del Perlimplín lorquiano. La tradición de las aleluyas en España tiene como antecedente la introducción de la literatura destinada a las clases populares, conocidas como relaciones, romances de ciego, almanaques y gozos, las cuales fueron en un inicio llamadas «literatura de cordel» por estar expuestos a la venta en pliegos colgados de una cuerda. Las aleluyas aparecen con su estructura definitiva (pliegos con 48 viñetas, repartidas en ocho filas) a finales del siglo XVI. Desde ese momento y hasta el siglo XVIII se imprimieron en blanco y negro. En el XIX lo fueron en papel barato de colores y, en ocasiones, algunas se colorearon toscamente (García Castañeda, 2003). A dicha tradición pertenece el personaje de Don Perlimplín, rescatado por Lorca, cuya importancia radica en ser la primera aleluya en incorporar pareados al pie de cada viñeta (Ucelay, 1990: 18-26).

La influencia de las aleluyas tiene presencia en la obra lorquiana en el aspecto visual para posibilitar «perspectivas ingenuas» (Ucelay, 1990: 24), acordes al tono de la farsa. Éstas se reflejan en las instrucciones escénicas, que destacan la preeminencia de los colores negro y verde, para dar un efecto «plano» del ambiente donde se mueven los personajes: «Paredes verdes con las sillas pintadas en negro» (253), o bien, «las perspectivas están equivocadas deliciosamente. La mesa con todos los objetos pintados como en una “Cena” primitiva» (274).

Las perspectivas del escenario «equivocadas deliciosamente» parecen tener, a su vez, relación con el concepto del «teatro planista», mencionado en una carta de 1922 que Lorca dirige a Melchor Fernández Almagro, a propósito de la representación en teatro de guiñol del Auto de los reyes magos que el poeta realizó en 1923 con motivo de la fiesta del Día de Reyes ${ }^{8}$. El con-

\footnotetext{
${ }^{8}$ Sobre esta representación, Ucelay relata: «Hermenegildo Lanz había copiado, para la ocasión, las figuras del códice medieval de Alberto Magno, conservado en la Universidad
} 
cepto del «teatro planista» se sustenta en el intento de dar la impresión en el escenario de una estampa en movimiento. Don Perlimplín mantiene relación con este concepto por «este atrevido intento de representar un aleluya, es decir, de moverla, de hacerla vivir» (Ucelay, 1990: 24).

Este efecto, muy bien logrado en los primeros cuadros, pierde fuerza en el último. La acotación sobre el escenario sólo señala: «Jardín de cipreses y naranjos» (280). Aunque la instrucción es escueta, implica un cambio en el ambiente escenográfico, dotándolo quizá de tintes más realistas. La presencia de los rosales, donde se esconde Perlimplín, así como los comentarios: «cruza el jardín cautelosamente» (284) o «Mirando al jardín» (286), llevan implícito un efecto de profundidad. Este cambio de escenario se presenta como un mecanismo más de extrañamiento, un cambio perceptual que se traducirá en recurso para lograr un nuevo efecto, ahora con tintes trágicos. Ricardo Doménech intuye también la carga semántica de la transformación del escenario en este cuadro, y señala el jardín como el espacio más «interesante» de la obra:

Aunque el jardín pertenece aún a la casa, hace pensar en el bosque de Bodas de sangre: en un fuera típicamente lorquiano. Sin embargo, para llegar a este espacio mágico del cuadro III, el autor ha diseñado un acceso sumamente original, modificando nuestra manera de mirar [...] Este cambio nos alerta sobre el que ahora se inicia en la acción dramática: de la farsa a la tragedia, del arquetipo del viejo cornudo al héroe trágico, de la «moral ridícula de las gentes» a la luz moral del pensamiento trágico (2008: 245).

El cambio perceptual se refuerza con el comentario de Marcolfa: «Antes todo estaba liso», refiriéndose al estado de las cosas previo a los cambios indescifrables que ha sufrido Perlimplín, quien se muestra ahora imbuido en una consciencia del mundo distinta, más profunda: «Antes no podía pensar en las cosas extraordinarias que tiene el mundo... Me quedaba en las puertas... En cambio ahora... El amor de Belisa me ha dado un tesoro precioso que yo ignoraba... ¿Ves? Ahora cierro los ojos y... veo lo que quiero...» (280-281).

Dicho cambio implica la disolución del efecto cómico y de la farsa, para hacer entrar a la obra en un ambiente dispuesto hacia un tono más grave. El último reducto del tono cómico corresponde a la canción del honor perdido de Perlimplín:

PERLIMPLÍN.— ¡Porque Don Perlimplín no tiene honor y quiere divertirse! ¡Ya ves! Esta noche vendrá el nuevo amante de mi señora Belisa. ¿Qué he de hacer sino cantar?

(Cantando)

de Granada, que pintadas y recortadas en cartón se movían sobre un fondo de miniaturas del mismo códice reproducidas en un telón y forillo, produciendo la impresión de una estampa en movimiento. Esta representación fue hecha en un teatro de guiñol cuya embocadura tendría apenas metro y medio de ancho, y en el que las figuras fueron movidas por el mismo Federico y su hermana Concha» (1990: 43). 
¡Don Perlimplín no tiene honor!

¡No tiene honor! (282).

Sin embargo, la escena no puede producir una risa franca, porque hay una carga velada de patetismo que es reconocida por la misma Marcolfa, quien llorando dice: «¡Me da miedo de oírlo!» (282). El hecho de que esta «burla» sea enunciada por quien es el objeto de ella, anula el efecto de la ridiculización y, por el contrario, carga al enunciado de un sentido perturbador, casi siniestro.

La reiteración de la muerte, cada vez más acentuada, así como la aparición de símbolos, van creando una tensión dramática que dirige al espectador no ya a un presentimiento, sino a la certidumbre de que un drama verdadero se está desarrollando ante sus ojos. La observación de Lorca anotada al principio de este escrito, sobre su intención de que «el drama debe estar en el público pero no en los personajes» adquiere total significado, porque, a partir de la tensión entre los tonos, el dramatismo desnudo de este último cuadro será la confirmación, como dirían los duendes, «de los secretos que ya sabía», pero que debían mantenerse ocultos para ser sublimados por Perlimplín, por el hombre con alma, ya no el monigote.

El dramatismo ha tomado forma en el espacio, lúgubre por la presencia de símbolos funestos, como el ciprés, la luna y el ruiseñor, todos ellos perfilando las acciones hacia el desenlace trágico. El cuadro se convierte así en la preparación de un acto ritual: la muerte de Perlimplín, delicadamente preparada para convertirlo en víctima sacrificial del amor.

La crítica ha anotado la muerte de Perlimplín como la de un héroe trágico, pero esta noción debe entenderse en el personaje no porque sea un héroe despeñado en la irrevocabilidad de su destino o porque concentre un deseo o una acción que le resultan fatales, sino porque en él se verifica la imposibilidad de una relación armoniosa entre el hombre y su mundo, ya que excluye la posibilidad de una comunicación genuina. Por ello, como señala el viejo Perlimplín, su victoria radica en el poder de su imaginación, en su capacidad para desplegar la realidad y darle otra faz. Si en uno de los lados de esa realidad Perlimplín es el «Viejo verde, monigote sin fuerzas», en la otra es lo que su imaginación le permite: «músculos jóvenes y labios de ascuas» (287).

El juego del ocultamiento es llevado hasta las últimas consecuencias, porque sólo así puede engañar a la realidad que lo disminuye y carcome, para regalarse el único instante permitido de realización: la muerte.

BELISA.-—QQué has hecho?

PERLIMPLÍN.-(Moribundo.) ¿Entiendes?... Yo soy mi alma y tú eres tu cuerpo... Déjame en este último instante, puesto que tanto me has querido, morir abrazado a él.

BELISA.—(Se acerca medio desnuda y lo abraza.) Sí... ¿pero y el joven?... ¿Por qué me has engañado?

PERLIMPLÍN.—¿El joven?... (Cierra los ojos.) (287-288). 
A la «luz mágica» de la escena final, Perlimplín se convierte, sublimado por la muerte, en alegoría de la certidumbre lorquiana de que el alma es una zona oscura, y el único acceso a ella es la imaginación poética. Pero para ello, hay que adentrarse «en ramas de zarzamora y erizos de vidrio para que se hieran las manos que la buscan» (García Lorca, 1984: 15). Esta certidumbre funciona como último mecanismo de extrañamiento, pero que se filtra no sólo en la realidad representada, sino en la experiencia vital del espectador/lector.

\section{BIBLIOGRAFÍA CITADA}

Bergson, Henri (1973). La risa. Ensayo sobre la significación de lo cómico. María Luisa Pérez Torres (trad.). Madrid: Espasa - Calpe.

Bou, Enric (2000). «Rostros de un rostro: aspectos visuales de Don Perlimplín», en Andrés Soria Olmedo, María José Sánchez Montes y Juan Varo Zafra (coord.), Federico García Lorca, Clásico Moderno, 1898-1998: Congreso Internacional 1998. Granada: Diputación de Granada, pp. 77-94.

Doménech, Ricardo (2008). García Lorca y la tragedia española. Madrid: Fundamentos.

Edwards, Gwynne (1983). El teatro de Federico García Lorca. Carlos Marín Baró (trad.). Madrid: Gredos.

Ferguson, Francis (1998). «Don Perlimplín: El teatro-poesía de Lorca», en Gil IldefonsoManuel (ed.), Federico García Lorca. Madrid: Taurus, pp. 175-185.

Fernández Cifuentes, Luis (1992). «El viejo y la niña: tradición y modernidad en el teatro de García Lorca», en Dru Dougherty y M. ${ }^{a}$ Francisca Vilches de Frutos (ed.), El teatro en España. Entre la tradición y la vanguardia (1918-1939). Madrid: Consejo Superior de Investigaciones Científicas - Fundación Federico García Lorca, pp. 89-101.

García Castañeda, Salvador (2003). «Don Perlimplín, Don Crispín y otras vidas de aleluyas», Salina: Revista de Lletres. 17, pp. 103-109.

García Lorca, Federico (1984). Conferencias, 2. Christopher Maurer (ed.). Madrid: Alianza.

García Lorca, Federico (1990). Amor de Don Perlimplín con Belisa en su jardín. Margarita Ucelay (ed.). Madrid: Cátedra.

García Lorca, Francisco (1998). Federico y su mundo. Mario Hernández (ed.). Madrid: Alianza.

González del Valle, Luis T. (1980). El teatro de Federico García Lorca y otros ensayos sobre literatura española e hispanoamericana. Nebraska: Society of Spanish and SpanishAmerican Studies.

Guardia, Alfredo de la (1961). García Lorca. Persona y creación. Buenos Aires: Schapire.

Pavis, Patrice (1980). Diccionario de teatro. Dramaturgia, estética y semiología. Fernando Del Toro (trad.). Barcelona: Paidós.

Peral Vega, Emilio (2001). «Burla clásica-burla moderna: el personaje de Perlimplín», en Javier Huerta Calvo, Emilio Peral Vega y Jesús Ponce Cárdenas (eds.), Tiempo de burlas. En torno a la literatura burlesca del Siglo de Oro. Madrid: Verbum, pp. 223-244.

Peral Vega, Emilio (2008). «Del modernismo a la Guerra Civil», en Javier Huerta Calvo (dir.), Historia del teatro breve en España. Madrid: Iberoamericana - Vervuert, pp. 10741152.

Rubio Jiménez, Jesús (1992). «Tendencias del teatro poético en España (1915-1930)», en Dru Dougherty y M. ${ }^{a}$ Francisca Vilches de Frutos (ed.), El teatro en España. Entre la tradición y la vanguardia (1918-1939). Madrid: Consejo Superior de Investigaciones Científicas - Fundación Federico García Lorca, pp. 255-263. 
Shklovski, Viktor (2007). «El arte como artificio», en Tzvetan Todorov (comp.), Teoría de la literatura de los formalistas rusos. Ana María Nethol (trad.). México: Siglo XXI, pp. $55-70$.

Ucelay, Margarita (1990). «Introducción», en Federico García Lorca, Amor de Don Perlimplín con Belisa en su jardín. Madrid: Cátedra, pp. 9-250.

Fecha de recepción: 11 de julio de 2013.

Fecha de aceptación: 6 de febrero de 2014. 